Contract No. and Disclaimer:

This manuscript has been authored by Savannah River Nuclear Solutions, LLC under Contract No. DE-AC09-08SR22470 with the U.S. Department of Energy. The United States Government retains and the publisher, by accepting this article for publication, acknowledges that the United States Government retains a non-exclusive, paid-up, irrevocable, worldwide license to publish or reproduce the published form of this work, or allow others to do so, for United States Government purposes. 


\title{
A PROTOTYPE FOUR-INCH SHORT HYDRIDE (FISH) BED AS A REPLACEMENT TRITIUM STORAGE BED
}

\author{
J. E. Klein, E. G. Estochen, K. L. Shanahan, and L. K. Heung \\ Savannah River National Laboratory: Aiken, SC 29808,james.klein@srnl.doe.gov
}

The Savannah River Site (SRS) tritium facilities have used $1^{\text {st }}$ generation (Gen1) metal hydride storage bed assemblies with process vessels (PVs) fabricated from 3 inch nominal pipe size (NPS) pipe to hold up to $12.6 \mathrm{~kg}$ of $\mathrm{LaNi}_{4.25} \mathrm{Al}_{0.75}$ metal hydride for tritium gas absorption, storage, and desorption for over 15 years. The $2^{\text {nd }}$ generation (Gen2) of the bed design used the same NPS for the PV, but the added internal components produced a bed nominally $1.2 \mathrm{~m}$ long, and presented a significant challenge for heater cartridge replacement in a footprint limited glove-box.

A prototype $3^{\text {rd }}$ generation (Gen3) metal hydride storage bed has been designed and fabricated as a replacement candidate for the Gen2 storage bed. The prototype Gen3 bed uses a PV pipe diameter of 4 inch NPS so the bed length can be reduced below $0.7 \mathrm{~m}$ to facilitate heater cartridge replacement. For the Gen3 prototype bed, modeling results show increased absorption rates when using hydrides with lower absorption pressures. To improve absorption performance compared to the Gen2 beds, a LaNi $_{4.15} \mathrm{Al}_{0.85}$ material was procured and processed to obtain the desired pressure-compositiontemperature (PCT) properties. Other bed design improvements are also presented.

\section{INTRODUCTION}

For over 15 years, the Savannah River Site (SRS) Tritium Facilities have used metal hydride storage beds ${ }^{1,2}$ with up to $12.6 \mathrm{~kg}$ of $\mathrm{LaNi}_{4.25} \mathrm{Al}_{0.75}$ (LANA0.75) for process gas absorption, storage, and desorption. The initial design - $1^{\text {st }}$ generation (Gen1) storage beds contain the metal hydride in a 3 inch NPS schedule 40 pipe process vessel (PV). The Gen1 beds use a thermal swing of hot and cold nitrogen, inside a larger pipe vessel that contains the PV, for gas desorption and absorption.

A $2^{\text {nd }}$ generation (Gen2) metal hydride bed was developed, ${ }^{3,4}$ using the same pipe NPS and hydride alloy as the Gen1 beds, but had design improvements such as an internal thermowell, two heaterwells, an in-bed accountability (IBA) U-tube, aluminum heat transfer foam, and hydride divider plates. The Gen2 bed, developed as a Passively-Cooled, Electrically heated hydride (PACE) Bed, utilizes electric heaters for desorption and much lower forced atmosphere cooling flow rates than the Gen1 beds for gas absorption. These beds are sometimes referred to as Forced-Atmosphere (glove box nitrogen) Cooled, Electrically heated (FACE) Beds or PACE Beds operating in FACE mode and are currently in production operations.

A $3^{\text {rd }}$ generation (Gen3) metal hydride storage bed has been developed that utilizes 4 inch NPS schedule 40 pipe for the PV. Previous testing determined that schedule 40 pipe wall thickness was sufficient for the PV to meet ASME Section VIII, Division 1 pressure vessel code allowable design limits. ${ }^{5}$ The use of a larger diameter PV for the Gen3 bed, containing the same mass of hydride as the Gen 1 and Gen2 beds, results in a shorter bed length. The Gen3 bed length will facilitate heater cartridge replacement and reduce required glove box space for new bed deployments.

This paper describes the design features of the Gen3 prototype bed assembled for testing. The rationale for using a lower pressure hydride material for improved absorption performance, and the production of this hydride material, is also discussed.

\section{BACKGROUND}

The Gen 1 bed length was approximately $0.91 \mathrm{~m}$ (3 feet). The Gen2 bed length increased to approximately $1.22 \mathrm{~m}$ (4 feet) long even though it used the same PV pipe NPS and was filled with the same hydride mass and alloy composition as the Gen1 bed. The increased Gen2 bed length was necessary to compensate for PV volume occupied by aluminum foam, divider plates, heaterwells, thermowells, and the IBA U-tube. ${ }^{3}$

Locating Gen2 beds in a glove box with over $1.2 \mathrm{~m}$ of clearance for heater removal and replacement was a challenging design issue. The use of 4-inch NPS standard schedule pipe for the Gen3 bed results in a much shorter, $12.6 \mathrm{~kg}$ capacity metal hydride bed. The development of the Four-Inch Short Hydride (FISH) Gen3 bed reduced the overall bed length to approximately $0.7 \mathrm{~m}$ (25 inches). 


\section{EXPERIMENTAL}

\section{III.A. Hydride Selection and Development}

Gas absorption by the Gen1 beds is accomplished by supplying large flows of cold gas through the jacket of the bed. Gas absorption by the LANA0.75 in the Gen2 beds is much slower than the Gen1 beds since the cooling gas flow rate through the jacket of the Gen2 beds is much slower and slightly lower than glove box temperatures.

The Gen2 bed absorption rate could be increased by use of a lower pressure hydride. The absorption rate studies for the prototype PACE bed used a nominal $\mathrm{LaNi}_{4.70} \mathrm{Al}_{0.3}$ (LANA0.30) material. ${ }^{3}$ It was decided to investigate the use of a different, lower absorption pressure, LANA material for the Gen3 bed to improve absorption performance.

Additional protium pressure-compositiontemperature (PCT) isotherm data were collected for varying amounts of $\mathrm{Al}$ substitution in several $\mathrm{LaNi}_{5-\mathrm{X}} \mathrm{Al}_{\mathrm{X}}$ (LANAX) materials: $X$ equal to $0.3,0.75,0.85$, and 1.0. Isotherms at two or more temperatures were measured to calculate hydride heat of formation data $(\Delta \mathrm{H})$ which for LANA0.3, LANA0.75, LANA0,85, and LANA1.0 were -33.81, -44.39, -43.20, and -43.35 kJ/mole- $\mathrm{H}_{2}$, respectively. The inflection points where the $\alpha+\beta$ phase transitioned to pure $\beta$-phase material were $0.88 \mathrm{H} / \mathrm{M}, 0.63$ $\mathrm{H} / \mathrm{M} 0.58 \mathrm{H} / \mathrm{M}$, and $0.50 \mathrm{H} / \mathrm{M}$ for LANA0.3, LANA0.75, LANA0.85, and LANA1.00, respectively where $\mathrm{H} / \mathrm{M}$ is the atomic hydrogen-to-metal ratio. These data were fit to a multi-parameter model for calculating PCT properties for each of the hydrides using a six parameter model as described elsewhere. ${ }^{6}$

The procedure used to estimate PACE bed absorption rates for different metal hydride materials first requires using previous PACE bed absorption data $^{3}$ to generate a correlation of absorption rate as a function of absorption temperature driving force. The steps were 1) Convert the experimental absorption data into absorption flow rate per $\mathrm{kg}$ of material at each bed loading $(\mathrm{H} / \mathrm{M})$ value, 2) Use the experimental absorption pressure $\left(\mathrm{P}_{\mathrm{abs}}\right)$, the experimental $\mathrm{H} / \mathrm{M}$ values and calculate the equilibrium temperature $\left(\mathrm{T}_{\mathrm{eq}}\right)$ using the six parameter model at each $\mathrm{H} / \mathrm{M}$ value, 3) Construct a plot of absorption rate per kg versus absorption temperature driving force $(\Delta \mathrm{T})$ which is equal to $\mathrm{T}_{\mathrm{eq}}$ minus the ambient temperature during the absorption test, and 4) Fit a regression model to these data so an absorption rate can be calculated for a given $\Delta \mathrm{T}$.

To estimate the bed absorption rate for a different hydride material, 1) Select $\mathrm{P}_{\mathrm{abs}}$, and at various $\mathrm{H} / \mathrm{M}$ values, use the six-parameter model for that hydride material to calculate $\mathrm{T}_{\mathrm{eq}}$ and thus a $\Delta \mathrm{T}$ value as a function of $\mathrm{H} / \mathrm{M}, 2)$ Use the $\Delta \mathrm{T}$ value to calculate an absorption rate from the previously developed correlation, 3) Convert absorption rate from rate per $\mathrm{kg}$ to absolute rate, and 4) Reduce the absorption rate by accounting for the decay heat of tritium generated within the hydride.

The shortening of the $\alpha+\beta$ plateau region as $X$ increases reduces the capacity of the bed. Equivalent bed gas capacities are $9.34 \mathrm{~kg}, 12.6 \mathrm{~kg}, 13.6 \mathrm{~kg}$, and $15.6 \mathrm{~kg}$ of LANA0.3, LANA0.75, LANA0.85, and LANA1.0, respectively where the $\alpha+\beta$ transition region ends. Figure 1 shows estimated absorption rates for beds with the same storage capacity for $\mathrm{P}_{\mathrm{abs}}$ of $273 \mathrm{kPa}$ (1900 torr) and a jacket cooling rate of 100 SLPM.

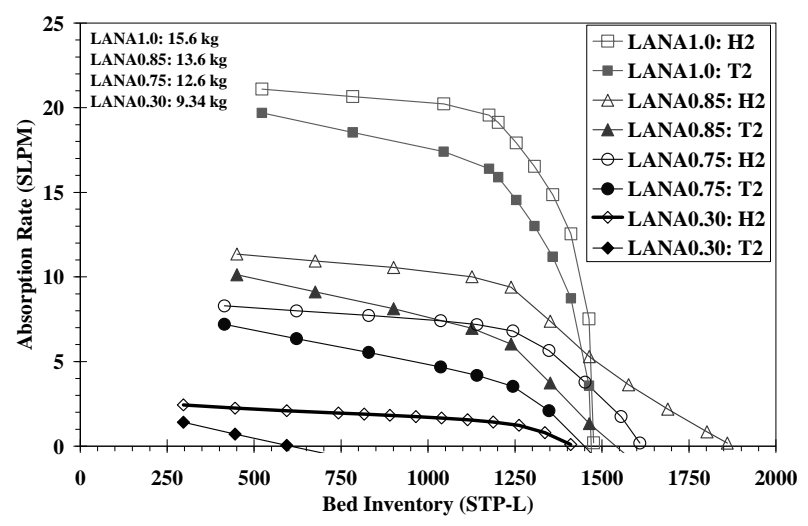

Fig. 1. Estimated Rates For LANA Hydrides.

Figure 1 shows LANA1.0 would give the best absorption results, but uncertainty of $\mathrm{Al}$ segregation in the sample tested lead to the choice of LANA0.85 for the Gen3 prototype bed. LANA0.85 material was procured from GfE (GfE Metalle und Materialien $\mathrm{GmbH}$, Germany) as a broken pieces from a casting and crushed and sieved by Ergenics (Ergenics Corp., Ringwood, NJ, U.S.A)

Figure 2 shows the $80^{\circ} \mathrm{C}$ hydrogen isotherms for the "crushed" material which had no plateau, suggesting a highly disordered material. SEM images of crosssectioned particles showed a mixed phase content (Figure 3). Hydrogen Consultants, Inc. (HCI, Littleton, CO, U.S.A.) was contracted to anneal the material under Ar at $\sim 900-1000^{\circ} \mathrm{C}$ for 100 hours. Some sintering of the material occurred during the annealing process and the material was broken up so it could be poured through $\mathrm{Al}$ foam for bed assembly. The annealing produced a material with low secondary phase content (Figure 3) and well-formed isotherms shown in Figure 2 as "annealed" isotherms. 


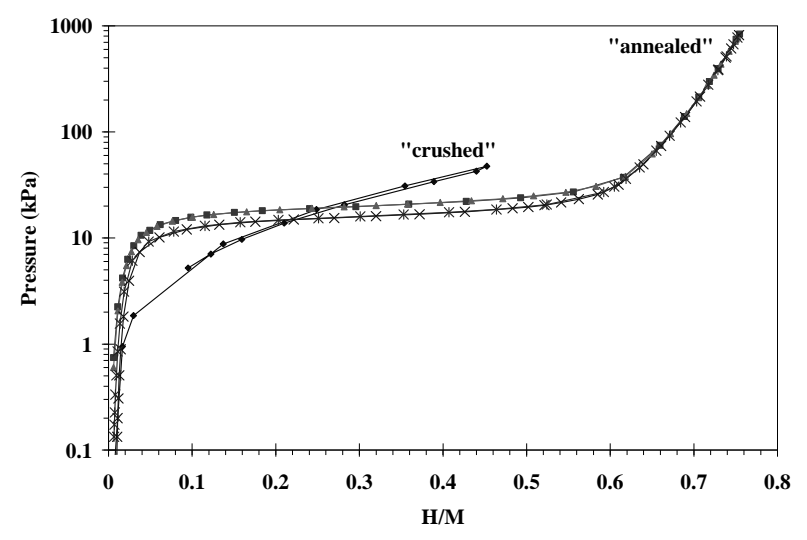

Fig. 2. GfE LANA0.85 $80^{\circ} \mathrm{C} \mathrm{H}_{2}$ Isotherms.

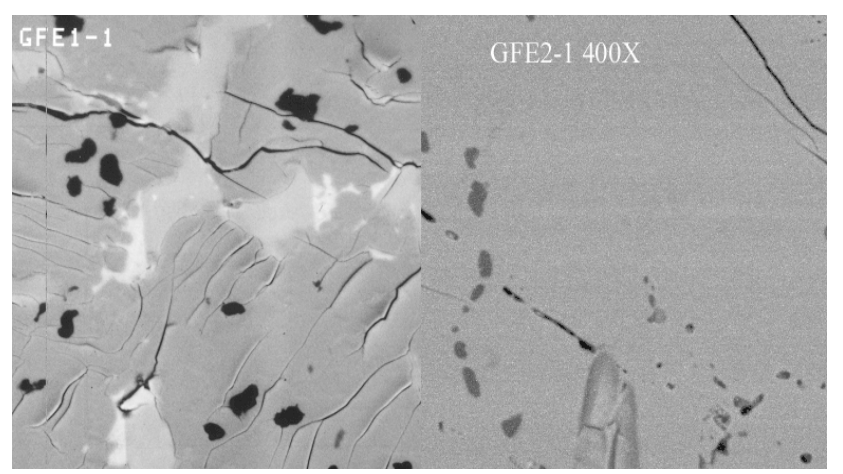

Fig 3. SEM pictures of unannealed (left, 530X) and annealed (right, 400X) GfE LANA0.85 material

\section{III.B. Hydride Bed Design}

Figure 4 shows the general configuration of the prototype FISH bed. The flat cap near the tube fittings was added to mate with a 5 inch NPS jacket pipe for cooling which produces a final bed length of $\sim 0.8 \mathrm{~m}$ (31 in). The $0.635 \mathrm{~m}$ (25 in) long PV was fabricated from, 4inch NPS schedule 40 (4.5 inch O.D., 0.237 inch wall thickness), 316/316L stainless steel pipe with flat end caps and had an internal volume of approximately $4.10 \mathrm{~L}$.

As seen in Figure 4, the bed was divided into four segments or cells, using 5 micron porous metal divider plates to allow gas flow between cells, but also restrict hydride material movement along the length of the bed. Between each divider plate, aluminum foam having 7-9 wt $\%$ density and 10 pores per inch was used to improve heat conduction throughout the metal hydride. As a final thermal performance improvement, eight 24 in long, 3/8 in wide, 1/16 in thick 316L stainless steel fins were seal welded to the exterior of the PV.

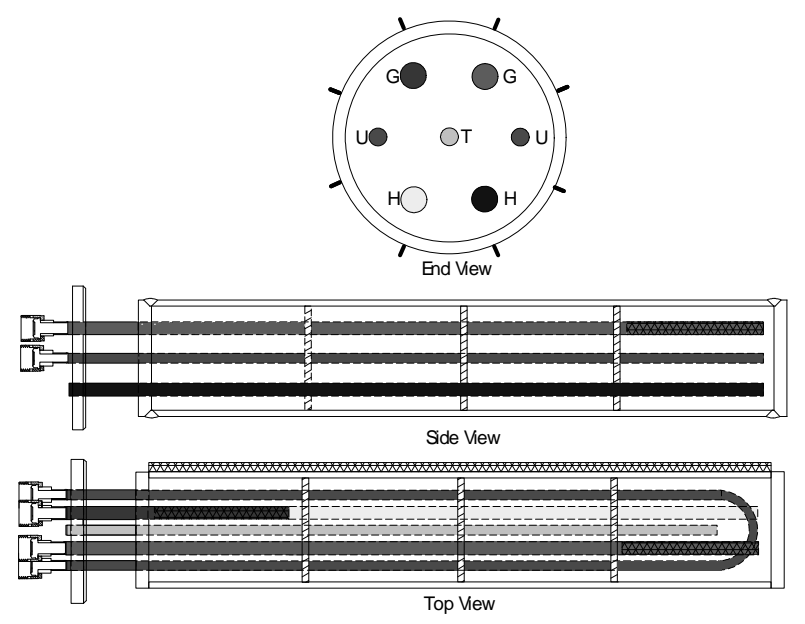

Fig. 4. Prototype FISH Bed

The one PV cap was penetrated by three $0.95 \mathrm{~cm}$ (3/8 in), O.D. tube ends, two $1.27 \mathrm{~cm}$ (0.5 in) O.D. tubes, and two $1.59 \mathrm{~cm}$ (0.625 in) O.D. tubes. The $0.95 \mathrm{~cm}$ (3/8 in), O.D. central tube was used as a thermowell ("T" in Figure 4), with the other two $0.95 \mathrm{~cm}$ (3/8 in), O.D. penetrations used for the IBA U-tube ("U" in Figure 4). When in operation, all three $3 / 8$ inch diameter tubes would be at the same mid-bed elevation, as indicated in the upper view of Figure 4.

Gas supply/removal for the bed uses two $1.27 \mathrm{~cm}$ (0.5 in) O.D. tubes ("G” in Figure 4) with 12.7 cm (5 in) of the in-bed end fabricated from tubular 5 micron sintered metal. The shorter gas tube, only passing into the first bed cell, was used for gas extraction, and the nearly full bed length tube for gas addition. During operation, these gas tubes would be the highest elevation tubes in the bed, as shown in the top view of Figure 4. The lowest elevation tubes, as shown in the top view in Figure 4, correspond to the two $1.59 \mathrm{~cm}$ (0.625 in) O.D. tubes used as heaterwells ("H" in Figure 4). All tubes, excluding the short gas tube extend for nearly the full length of the bed.

\section{RESULTS}

The various components of the FISH bed are shown in Figure 5 prior to assembly. The cast, crushed, and annealed LANA0.85 metal hydride material was used to fill the prototype FISH bed. Bed assembly consisted of placing the empty bed in a vertical orientation with the open end facing upwards, and individually adding foam pieces, tubes, hydride and divider plates until all internals were installed. The short gas inlet tube was the last component added to the bed, after which the final cell was filled with hydride, the end cap welded into place, and the 
tubes welded at cap penetration locations. Each of the four bed cells were loaded with $3.4 \mathrm{~kg}$ of hydride material which resulted in approximately $80 \%$ of the total void volume to be occupied by hydride material. The total LANA0.85 mass of $13.6 \mathrm{~kg}$ matches the gas storage capacity of $12.6 \mathrm{~kg}$ of LANA0.75.

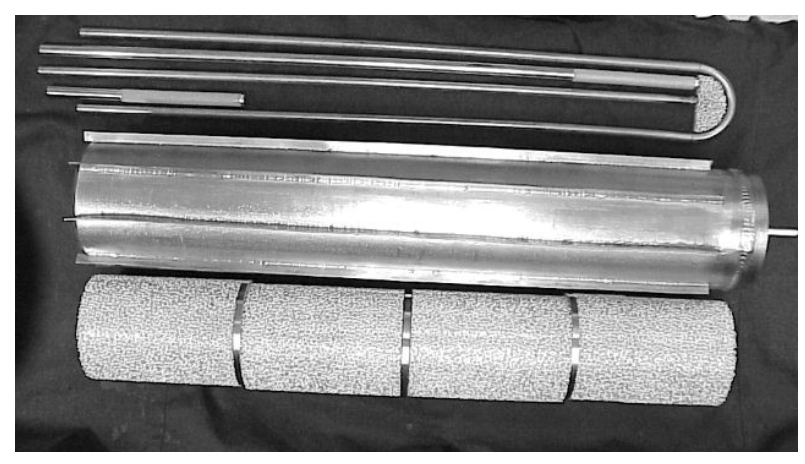

Fig. 5. FISH Bed Pre-Assembly Components

After final closure of the bed by welding the end cap and tube penetrations, the sealed assembly was subjected to pneumatic and leak tests to meet ASME Section VIII Division 1 requirements with a design pressure and temperature of $4.24 \mathrm{MPa}(600 \mathrm{psig})$, and $260^{\circ} \mathrm{C}\left(500^{\circ} \mathrm{F}\right)$. As a final fabrication step, specific high strain locations were marked for surface treatment to obtain an oxide free $40 \mu$ finish to ensure proper strain gage bonding.

\section{DISCUSSION}

Testing of the FISH bed prototype will be conducted in several phases. Before bed testing, strain gauges will be attached and the bed baked to cure the strain gauge epoxy. The first testing phase will be bed activation and confirmatory PV strain measurements during hydriding to verify previously obtained results. ${ }^{5}$

Once the bed wall stresses have been confirmed to be within ASME allowable limits, an absorption/desorption test program similar to that performed for the Gen2 bed $^{3}$ will be conducted after the addition of the bed's outer jacket. Tests will also be conducted using the two gas filter tubes to determine operating scenarios for removal of inert gases during gas absorption processes. Removal and reinsertion or replacement of the heater cartridges will be demonstrated during the test program. The final phase of testing will be a series of tests to determine the measurement uncertainty of the IBA measurement technique.

\section{CONCLUSIONS}

A prototype $3^{\text {rd }}$ generation hydride bed has been constructed for testing at the SRS, developed as a direct replacement for Gen2 beds, and is expected to exceed the absorption performance of the Gen2 beds by the use of a LANA0.85 hydride and two process filter tubes to aid the removal of inert gases during desorption. The bed design life is expected to exceed the life of the heaters due to the ability to replace the heaters while located within a glove box. Replacement of Gen1 beds with FISH beds is also possible, but will require additional glove box modifications to handle the additional heat load to the glove box atmosphere.

\section{ACKNOWLEDGMENTS}

The authors would like to thank Jody Dye for her contributions to this work. This manuscript has been authored by Savannah River Nuclear Solutions, LLC under contract No. DEAC09-08SR22470 with the U.S. Department of Energy. The United States Government retains and the publisher, by accepting this article for publication, acknowledges that the United States Government retains a non-exclusive, paid-up, irrevocable, worldwide license to publish or reproduce the published form of this work, or allow others to do so, for United States Government purposes.

\section{REFERENCES}

[1] M. S. Ortman, L. K. Heung, A. Nobile, and R. L. Rabun, "Tritium Processing at the Savannah River Site: Present and Future,” J. Vac. Sci. Technol. A, 8 (3), 2881 (1990).

[2] J. E. Klein, "A Summary of Tritium In-Bed Accountability for 1500 Liter $\mathrm{LaNi}_{4.25} \mathrm{Al}_{0.75}$ Storage Beds,” Fusion Technol., 41, 542 (2002).

[3] J. E. Klein, J. R. Brenner, and E. F. Dyer, "Development of a Passively Cooled, Electrically Heated Hydride (PACE) Bed," Fusion Sci. and Technol., 41, 782 (2002).

[4] J. E. Klein, "In-Bed Accountability Development for A Passively Cooled, Electrically Heated Hydride (PACE) Bed," Fusion Sci. and Technol., 48, 416 (2005).

[5] E. G, Estochen and J, E. Klein, "Metal Hydride Wall Stress Measurements on a Four-Inch Short (FISH) Bed ," Fusion Sci. and Technol., 48, 79 (2005).

[6] H. Bjurstrom, S. Suda, and D. Lewis, “A Numerical Expression for the P-C-T Properties of Metal Hydrides,” J. Less-Common Metals, 130, pp. 365-370 (1987). 